\title{
An IFRS 2 AND FASB 123 (R) COMPATIBLE MODEL FOR THE VALUATION OF EMPLOYEE STOCK OPTIONS
}

\author{
Manuel Ammann (manuel.ammann@unisg.ch) and \\ Ralf Seiz (ralf.seiz@unisg.ch) \\ Swiss Institute of Banking and Finance, University of St. Gallen, \\ Rosenbergstrasse 52, CH-9000 St. Gallen, Switzerland \\ Tel.: (41) 71-2247090; Fax: (41) 71-2247088
}

\begin{abstract}
We show how employee stock options can be valued under the new reporting standards IFRS 2 and FASB 123 (revised) for sharebased payments. Both standards require companies to expense employee stock options at fair value. We propose a new valuation model, referred to as Enhanced American model, that complies with the new standards and produces fair values often lower than those generated by traditional models such as the Black-Scholes model or the adjusted Black-Scholes model. We also provide a sensitivity analysis of model input parameters and analyze the impact of the parameters on the fair value of the option. The valuation of employee stock options requires an accurate estimation of the exercise behavior. We show how the exercise behavior can be modeled in a binomial tree and demonstrate the relevance of the input parameters in the calibration of the model to an estimated expected life of the option.
\end{abstract}

Keywords employee stock options, executive compensation, IFRS 2, FASB $123(\mathrm{R})$

JEL Classification G13, G30

\section{Introduction}

In many firms, employee stock option plans are an important part of employee remuneration. In the last decade, there has been a debate by accounting standard-setters, firms, academics, and politicians about whether employee stock options should be expensed. Recently, the International Accounting Standards Board (IASB) and the Financial Accounting Standards Board (FASB) have issued their share-based payment standards IFRS 2 and
FASB No. 123 (revised), respectively. Both standards require employee stock options to be recognized as an expense. This expense is measured at the fair value of the employee stock option, determined at the date of grant. Now that the recognition issue has been determined, the focus has shifted to the application of these standards, specifically to how the fair value of employee stock options should be computed. Given the fact that there is currently no generally accepted model, the Standard Boards decided not to put forth a valuation model. The guidance provided by the standards focuses on limiting the measurement possibilities and states that the accounting objective is to estimate the fair value of the employee stock options.

Employee stock options have a number of characteristics that prevent their valuation by standard option-pricing models (such as vesting or blocking periods, non-transferability, exit rates, etc.). By neglecting these restrictive features of employee stock options, standard models such as the BlackScholes model or the standard binomial model overestimate the value of the options. One of the first papers on valuing employee stock options is SMITH and ZIMMERMAN (1976), which uses the Black-Scholes-Merton model. JENNERGREN and NASLUND (1993) modify the Black-Scholes model for forfeitures and early exercise, because employees leave the firm. HUDDART (1994), KULATILAKA and MARCUS (1994), and RUBINSTEIN (1995) develop binomial models 
that determine the employee stock option exercise scheme that maximizes the expected utility of the employees. CUNY and JORION (1995) model the possibility that the employee might leave the firm prior to maturity and, consequently, have to exercise or forfeit the options. LAMBERT et al. (1991) show that employee stock options can be worth substantially less to risk-averse and nondiversified employees. CARPENTER (1998), HULL and WHITE (2004), and AMMANN and SEIZ (2004) develop binomial models that extend the ordinary American option-pricing model by introducing exogenous early exercise and forfeiture. The model of CARPENTER (1998) assumes an exogenous stopping rate. The HULL and WHITE (2004) binomial model assumes an exogenous employee exit rate, which is analogous to the stopping rate of CARPENTER (1998), and an exogenous early exercise multiple (of the strike price) at which voluntary exercise occurs. A similar model of AMMANN and SEIZ (2004) adjusts the options strike price to account for early exercise. The models demonstrate that simple contingentclaims models can describe the exercise scheme just as well as complex utility-maximizing models. AMMANN and SEIZ (2004) present a detailed model comparison and investigate a utility-maximizing model as proposed by KULATILAKA and MARCUS (1994), HUDDART (1994), and RUBINSTEIN (1995), a recent model by HULL and WHITE $(2002,2003,2004)$, and the model proposed by the Financial Accounting Standards Board (1995), referred to as the adjusted BlackScholes model (or the FASB 123 model). They show that, with the exception of the adjusted Black-Scholes model and the standard BlackScholes and American models, these models produce virtually identical option prices if they are calibrated to the same expected life. In other words, even though the models tested derive their exercise policies using completely different approaches, the pricing effect of the different exercise schemes is negligible as long as the expected life of the option is the same. Therefore, the drawback of the dependence on unobservable and hard-to-estimate parameters, such as the risk aversion coefficient in the utility-maximizing model, can be overcome by using the expected life, which is much easier to estimate, to calibrate the model.

In this paper, we present a new valuation model for employee stock options that is in compliance with the requirements of both standards IFRS 2 and FASB No.123 (R). Furthermore, we provide a sensitivity analysis of two categories of model input parameters: First, the plan parameters that can be specified by the issuing firm in the employee stock option plan before the grant date (such as maturity, vesting or blocking period, strike price and grant date). Second, the estimated parameters that must be determined at the date of grant (such as expected volatility, expected dividend yield, risk-free rate, expected post-vesting exit rate and the expected life of the option). We analyze the influence of these parameters on the fair value. Moreover, we discuss how the exercise scheme can be estimated for a given set of input parameters. The analysis shows that the expected life of the employee stock option or the exercise scheme has to be determined by considering the model input parameters.

\section{Valuation Model Requirements under the New Reporting Standards}

Under the new International Financial Reporting Standard 2 (IFRS 2 2004) and the revised Statement of Financial Accounting Standards No. 123 by the Financial Accounting Standard Board (FASB No. 123 (R), Share-Based Payment), companies are required to expense employee stock options at fair value. The standards set out rules on how to account for share-based payments. Both standards state that, to date, there is no particular option pricing model that is regarded as theoretically superior to the others. Entities should select whichever model is most appropriate in the 
circumstances. For many entities, circumstances might preclude the use of the standard BlackScholes-Merton model. However, the Standard Boards concluded that it was not necessary to prohibiting the use of the Black-Scholes-Merton formula and that generally closed-form models are one acceptable technique for estimating the fair value of employee stock options. Rather than prohibiting the use of the Black-Scholes-Merton formula, the Standard Boards concluded that the standards should provide guidance on selecting the most appropriate model and that it is sufficient to select a valuation technique that fits a firm's circumstances best. The Standard Boards stated that the effects of early exercise, i.e., the employees' option exercise scheme and post-vesting employee termination (exit of the firm) should be taken into account (and that these effects can be accommodated by lattice models). A more flexible model is likely to produce a more accurate estimate of the employee stock option's fair value. For instance, a lattice model can accommodate estimates of employees' option exercise behavior and post-vesting employment termination (postvesting exit-rate) during the option's contractual term (maturity), and thereby can reflect the effect of those factors better than an estimate based on a closed-form model (e.g., Black-Scholes-Merton formula) with a single weighted-average expected life of the options.

The variables used to measure the fair value of an employee stock option have a significant impact on the valuation. Generally, the standards concluded that the following factors should be considered by applying an employee stock option pricing model: exercise price of the option $(X)$, contractual life (maturity) of the option $(T)$, price of the underlying share at grant date $(S)$, expected volatility of the share price $(\sigma)$, expected dividends or expected dividend yield $(D)$, risk-free interest rate $(r)$, and the effects of early exercise (the expected life of the option $(E L)$ and the postvesting exit $\left.\left(w_{2}\right)\right)$. Other factors can also be considered: the blocking periods, long live char- acter of employee stock options and factors that market participants would consider. The blocking period (a period where the employees cannot exercise their options) is not the same as the vesting period (period during which the specified vesting condition are to be satisfied, e.g. a service condition that requires the employee to complete the service period in the firm to receive the entitlement). Generally, for plain vanilla employee stock options, the two periods are identical (same beginning and end of the period).

A lattice model can accommodate estimates of employees' option exercise behavior and postvesting employment termination during the option's contractual term, and thereby can reflect the effect of those factors better than an estimate based on a closed-form model. Factors to consider in estimating the early exercise and the effect of non-transferability include: vesting and blocking periods, price of the underlying share, expected volatility of the underlying share, employees' historical exercise schemes and different exercise behaviors for homogenous groups with similar exercise behavior.

The standards require using a so-called "modified grant date method" to account for the forfeitures of options during the vesting period (the forfeiture rate is determined by the pre-vesting employee exit rate). This rule requires entities to measure the cost of employee services received in exchange for the employee stock options based on the grant-date fair value of the options. That cost will be recognized over the period during which an employee is required to provide service in exchange for the options i.e., - the requisite service period (usually the vesting period). No compensation cost is recognized for employee stock options for which employees do not render the requisite service. Furthermore, the standards require for determining the fair value of the employee stock options that no vesting conditions (except market conditions) be taken into account. Therefore, it is important to distinguish between the pre-vesting exit rate $\left(w_{1}\right)$, which is accounted 
for by using the modified grant date method, and the post-vesting exit rate $\left(w_{2}\right)$, which is an input parameter to determine the fair value of the employee stock option.

\section{The Enhanced American Model}

Employee stock options differ from standard exchange-traded options in important aspects (see, for example, RUBINSTEIN, 1995). Several researchers have noted the shortcomings of using traditional option formulas to value employee stock options.[1] In the following, we identify the three main differences and explain how they can be addressed in a valuation model for employee stock options:

Vesting or Blocking Period: Employee stock options can only be exercised after the vesting or blocking period $v$. Delayed vesting can be handled easily by modifying the standard binomial model such that exercise is not allowed during the vesting period.

Exit Rate: Employees may be forced to exercise unexercised but vested options prematurely upon leaving the firm. Thus, employee stock options are exercised earlier than optimally exercised standard American options. The probability of employees leaving the firm after the vesting period is modeled by the post-vesting exit rate $w_{2}$ and given for each period $\Delta t$ as $\left(1-\mathrm{e}^{-w_{2} t}\right)$. We assume that the post-vesting exit rate $w_{2}$ is constant over time. If the employee leaves after the vesting period $v$, the option is forfeited if it is out of the money and exercised (immediately) if it is in the money. Furthermore, if the employee does not leave after the vesting period, there are two possibilities: either the option will be voluntarily exercised or held.

Non-Transferability: Employees are not allowed to sell their employee stock options. Because of this non-transferability feature, a premature (early) exercise is often the only way of raising cash from the option. Several researchers have documented that employee stock options are exercised relatively early in their term, even when the underlying stock pays no dividends (see, for example, HUDDART and LANG, 1996). Such sub-optimal exercise reduces the option's value. The time when a particular employee exercises the option may depend on several factors such as risk-aversion, liquidity requirements, diversification motives, non-option-wealth, expected stock-return, utility function, underlying stock price, etc. Thus, an individual exercise scheme will be determined that characterizes an employee or a group of employees with similar exercising behavior. Therefore, for a group of employees of a certain exercise type, the expected life of the option can be estimated. For calculating the expected life, we use the conditional procedure described by HULL and WHITE (2002), which is an expectation conditional on the option vesting. Therefore, the expected life of a set of employee stock options is defined as the length of time that options remain unexercised on average given that they vest. We choose this definition for empirical convenience because only options that have vested need to be considered for empirical estimation of expected life. This definition implies that the expected life of the option is always smaller than the maturity because the exit rate is greater than zero after the vesting period. The expected life is not invariant to the probability measure. Our definition of expected life is a risk-neutral expected life. In risk-averse economies, employee stock options are exercised sooner than in risk-tolerant economies (see GARMAN 1989).

We present a new model for valuing employee stock options that conforms to the new reporting standards IFRS 2 and FASB 123 (revised), referred to as Enhanced American model[2] (EA model). It considers a vesting period (blocking period), the possibility that employees may leave the company after the vesting period (post- 
vesting exit), and early exercise due to the nontransferability.

The general approach is similar to an American model that is adjusted for the post-vesting exit rate and the vesting period, but this model explicitly incorporates the employee's early exercise policy. The incorporation of sub-optimal early exercise is simple: it consists only of an adjustment of the strike price of the option. Of course, the adjusted strike price is used only to determine the time of exercise, not to calculate the payoff of the option. The adjustment factor is denoted by a variable $M^{*}$ that can be interpreted as an exercise acceleration factor triggering premature or late exercise depending on its value.

We model the early exercise behavior of employees by assuming that exercise takes place whenever there is a positive intrinsic value and the exercise value adjusted by the factor $M^{*}$ is larger than the holding value (i.e., $\max \left(S_{i, j}-M^{*} \cdot X, 0\right) \geq$ $\left.e^{-r \Delta t} \cdot\left[p f_{i+1, j+1}+(1-p) f_{i+1, j}\right]\right)$ and the option has vested. For an exercise accelerator of $M^{*}=1$, the EA-model and the American model adjusted for the post-vesting exit rate and the vesting period are the same. For $M^{*}$ smaller and greater than one, the EA model accelerates or delays exercise, respectively, and thus allows for an individual, sub-optimal exercise policy. The Enhanced American model shows that by making a very small adjustment to the standard Americanmodel adjusted for the post-vesting exit rate and the vesting period, a model with all the employee stock option features described above can be obtained in a very simple way.

The exercise accelerator $M^{*}$ used in the Enhanced American model is similar to the multiple $M$ used in the HW-model (see HULL and WHITE 2004) because $M^{*}$ is also a multiple of the strike price $X$. However, in contrast to the HW-model, $M^{*}$ multiplied by the strike price $X$ represents a virtual strike price of a specific employee. In the EAmodel the employee decides to exercise the option if he is satisfied with the intrinsic value relative to his virtual strike price $M^{*} X$. The value of the option is maximized if the exercise accelerator equals one $\left(M^{*}=1\right)$. In contrast to the HW-model, where the best achievable exercise strategy is still sub-optimal, this maximum price implies an optimal exercise policy and is therefore equal to the price obtained by the American-model adjusted for the post-vesting exit rate and the vesting period.

The Enhanced American model is implemented with a generalized binomial-tree method. For the binomial-tree method, we use the standard specifications as originally proposed by COX et al., (1979). Suppose that there are $N$ time steps of length $\Delta t$ in the tree and that $S_{i, j}$ is the stock price at the $j$ th node of the tree at the time $i \Delta t$ and $f_{i, j}$ is the value of the employee stock option at this node. Define $S$ as the initial stock price, $X$ as the strike price of the option, $T$ as the maturity of the option (time-to-expiration), $\sigma$ as the volatility of the underlying stock, $r$ as the continuous risk-free rate, $D$ as the continuous expected dividend yield, $u$ and $d$ as the up- and down-movement factors of the stock price, and $p$ as the risk-neutral probability for an up-step. For the binomial-tree method, we used the following standard specifications, originally proposed by COX et al., (1979), for the volatility factors:

$$
\Delta t=\frac{T}{N} ; u=e^{\sigma \sqrt{\Delta t}} ; d=\frac{1}{u} ; p=\frac{e^{(r-D) \cdot \Delta t}-d}{u-d}
$$

The probability that the employee stock option will be terminated after the vesting period is $\left(1-e^{-w_{2} \Delta t}\right)$ in each period $\Delta t$ for a continuous post-vesting exit rate $w_{2}$. The decision rules in the binomial tree are modified accordingly:

The value of the employee stock option in each node of the tree is denoted by $f_{i, j}$ for time $i$ and node $j$. At maturity of the option $(i=N)$, the value of the option is given as the option's intrinsic 
value $f_{N, j}=\max \left(S_{N, j}-X, 0\right)$. For all other nodes $(0 \leq i \leq N-1)$, the rules are as follows:

- During the vesting period (if $i \Delta t<v$ ):

The value of the option is,

$$
f_{i, j}=e^{-r \Delta t} \cdot\left[p \cdot f_{i+1, j+1}+(1-p) \cdot f_{i+1, j}\right]
$$

- After the vesting period (if $i \Delta t \geq v$ ):

If there is an exit with probability $\left(1-e^{-w_{2} \Delta t}\right)$, the option will be exercised immediately and the exit value is given by the option's intrinsic value, namely $\max \left(S_{i, j}-X, 0\right)$. Therefore, the exit component of the option price will be the probability multiplied by the exit value: $\left(1-e^{-w_{2} \Delta t}\right) \cdot \max \left(S_{i, j}-X, 0\right)$.

If there is no exit with probability $e^{-w_{2} \Delta t}$, the option will either be exercised or held:

If the option is exercised, the no-exit component of the option price is

$e^{-w_{2} \Delta t} \cdot \max \left(S_{i, j}-X, 0\right)$.

If the option is held, the no-exit component of the option price is

$e^{-w_{2} \Delta t} \cdot \mathrm{e}^{-r \Delta t} \cdot\left[p \cdot f_{i+1, j+1}+(1-p) \cdot f_{i+1, j}\right]$.

The value of the option is the sum of these two components (exit and no exit):

If the option is exercised:

$$
\begin{aligned}
f_{i, j}= & \left(1-e^{-w_{2} \Delta t}\right) \cdot \max \left(S_{i, j}-X, 0\right) \\
& +e^{-w_{2} \Delta t} \cdot \max \left(S_{i, j}-X, 0\right) \\
= & \max \left(S_{i, j}-X, 0\right)
\end{aligned}
$$

If the option is held:

$$
\begin{aligned}
f_{i, j}= & \left(1-e^{-w_{2} \Delta t}\right) \cdot \max \left(S_{i, j}-X, 0\right)+e^{-w_{2} \Delta t} \\
& \cdot e^{-r \Delta t} \cdot\left[p \cdot f_{i+1, j+1}+(1-p) \cdot f_{i+1, j}\right]
\end{aligned}
$$

The rules for calculating the fair value of the option $f_{0,0}$ are: At the end nodes the value of the option is given as the option's intrinsic value $f_{N, j}=$ $\max \left(S_{N, j}-X, 0\right)$. For all other nodes $(0 \leq i \leq N-$ $1)$, the rules for calculating the value of the employee stock option are as follows:

- During the vesting period (if $i \Delta t<v$ ), the value of the option is calculated as

$$
f_{i, j}=e^{-r \Delta t} \cdot\left[p \cdot f_{i+1, j+1}+(1-p) \cdot f_{i+1, j}\right] .
$$

- After the vesting period (if $i \Delta t \geq v$ ):

If there is a positive intrinsic value (i.e., $S_{i, j}-$ $X>0)$ and the exercise criterion, i.e.,

$$
\begin{aligned}
\max & \left(S_{i, j}-M^{*} \cdot X, 0\right) \\
& \geq e^{-r \Delta t} \cdot\left[p f_{i+1, j+1}+(1-p) f_{i+1, j}\right]
\end{aligned}
$$

is satisfied, then the option will be exercised. Its value is therefore

$f_{i, j}=\max \left(S_{i, j}-X, 0\right)=S_{i, j}-X$

Otherwise, the option is held and its value is therefore

$$
\begin{aligned}
f_{i, j}= & \left(1-e^{-w_{2} \Delta t}\right) \cdot \max \left(S_{i, j}-X, 0\right) \\
& +e^{-w_{2} \Delta t} \cdot e^{r \Delta t}\left[p \cdot f_{i+1, j+1}+(1-p) \cdot f_{i+1, j}\right]
\end{aligned}
$$

The calculation of the risk-neutral expected life is as follows:[3] Define $L_{i, j}$ as the risk-neutral expected life of the option at time $i \Delta t$. The stock price is $S_{i, j}$. Set $L_{N, j}=0$ for the expected life at the end nodes. For all other nodes $(0 \leq i \leq$ $N-1)$, expected life is calculated as follows:

- During the vesting period (if $i \Delta t<v$ ), the option cannot be exercised and, according to the riskneutral valuation principle, the expected life, for a time increase of one binomial step $(\Delta t)$, is 
calculated as (the exit rate is ignored because the expectation is conditional)

$$
L_{i, j}=p \cdot L_{i+1, j+1}+(1-p) \cdot L_{i+1, j}+\Delta t
$$

- After the vesting period (if $i \Delta t \geq v$ ), expected life is calculated as follows:

If the option is exercised, then

$L_{i, j}=0$.

If the option is held, then

$$
\begin{aligned}
L_{i, j}= & \underbrace{\left(1-e^{-w_{2} \Delta t}\right) \cdot 0}_{=0}+e^{-w_{2} \Delta t} \\
& \cdot\left[p \cdot L_{i+1, j+1}+(1-p) \cdot L_{i+1, j}+\Delta t\right]
\end{aligned}
$$

The expected life of an option today, i.e., in the first node, is given by $L_{0,0}$.

\section{Sensitivity Analysis and Exercise Scheme of Employee Stock Options}

\subsection{Changing Input Parameters}

Plain vanilla employee stock options usually have a vesting period $(v)$ (generally this is a service condition, which requires the employee to complete this period of service and is identical to a blocking period where the options cannot be exercised) between one and four years and a maturity or time to expiration $(T)$ between four and ten years. Furthermore, firms are able to set the strike price $(X)$. Generally, the strike price is set to a value similar to the price of the underlying share $(S)$ at the grant date (at-the-money issue). Firms are also able to schedule the date of the grant and therefore firms can define indirectly the price of the underlying share in a certain range. Therefore, four input parameters $(v, T, X$ and $S)$ define the general character of the employee stock option. These parameters are defined by the stock option plan and we refer to these input parameters as the plan parameters. On the other hand, there are input parameters that have to be estimated at the date of grant. These parameters are the expected volatility $(\sigma)$, the risk-free rate $(r)$, the expected dividend yield $(D)$, the post-vesting exit rate $\left(w_{2}\right)$ and the expected life of the option $(E L)$. We refer to these input parameters as the estimated parameters.

In this section we analyze the implication of the plan and estimated input parameters on the fair value of employee stock options with option prices valued by the Enhanced American model, starting with a standard option described in Table 1. First, we perform a sensitivity analysis of the two categories of parameters and examine the effect on the fair value. Second, we discuss which parameters determine the exercise scheme.

The fair value of the employee stock option with the input parameters given in Table 1 valued with the Enhanced American model is $\$ 18.82$. In the following, we change the input parameters by $+10 \%$ and $-10 \%$ and determine the corresponding fair values. Furthermore, it is possible to rank the sensitivity of the parameters with respect to changes of their fair values. Below we show that certain input parameters can have a huge influence on the exercise scheme. First, the moneyness $(S / X)$

\section{Table 1: Input Parameters for the Standard Example}

\begin{tabular}{lll}
\hline Plan parameters (parameters & $S$ & $\$ 50$ \\
defined by the employee & $X$ & $\$ 50$ \\
stock option plan) & $T$ & 7 years \\
& $V$ & 3 years \\
Estimated parameters (parameters & $E L$ & 5 years \\
estimated at grant date) & $\sigma$ & $50 \%$ \\
& $r$ & $2.5 \%$ \\
& $D$ & $1.0 \%$ \\
& $w_{2}$ & $5.0 \%$ \\
\hline
\end{tabular}

Note:

Table 1 shows the input parameters for the standard example: price of the underlying share $(S)$, strike price $(X)$, maturity or time to expiration $(T)$, vesting period $(v)$, expected life of the option $(E L)$, expected volatility $(\sigma)$, risk-free rate $(r)$, expected dividend yield $(D)$, and post-vesting exit rate $\left(w_{2}\right)$. 
can trigger early or late exercise, second, the proportion between the vesting period and the maturity of the option $(v / T)$ defines the exercisable period and therefore restricts the expected life of the option, and third, the post-vesting exit rate $\left(w_{2}\right)$ can trigger early exercise of the options. There are two possibilities to specify an exercise scheme: (1) calibrate the model to the estimated expected life $(E L)$ for a given set of input parameters (mainly taking into account the moneyness, the proportion between the vesting period and the maturity and the post-vesting exit rate), and (2) calibrating the exercise scheme within the binomial tree (i.e., valuation with an estimated exercise accelerator $\left.M^{*}\right)$.

AMMANN and SEIZ (2004) show that the fair value is greatly affected by the expected life of the option. However, the expected life is restricted by the maturity $T$ and the vesting period $v$. In a first step, for changes of the maturity and the vesting period, we change the expected life such that the expected life is always in the middle of the exercisable period $(v+(T-v) / 2)$. Below we show that if there is no such adjustment of the expected life (i.e., estimating the expected life regardless of the proportion between the vesting period and the maturity), the exercise scheme varies greatly.

Table 2 shows the results of the sensitivity analysis for the two different parameter categories. For the plan parameters (input parameters that are defined by the employee stock option plan), the most sensitive parameter is the price of the underlying share $(S)$ at grant date, followed by the strike price $(X)$. This is similar to the standard Black-Scholes model, where option values increase with increasing stock prices and decreasing strike prices. Furthermore, Table 2 shows that the fair value increases with an increase of the maturity of the option. Intuitively not obvious is that the fair value of the option increases also with an increase of the vesting period. This is caused by the increase of the expected life ( 5.15 years instead of 5.00 years). In other words, the vesting period forces employees not to exercise their options sub-optimally. On the other hand, a short vesting period allows the employees to exercise their options relatively early (and sub-optimally) and therefore reduces the fair value. Later we show that the proportion between the vesting period and the maturity $(v / T)$ has the strongest influence on the exercise scheme and therefore on the fair value of the option.

For the estimated parameters (input parameters that must be estimated at the date of grant), the expected life $(E L)$ is the parameter with the greatest impact. The expected life defines the exercise scheme; an increasing expected life increases the fair value.[4] Similar to standard exchange-traded options, the volatility has also a significant influence on the fair value of the option. Both the risk-free rate and the expected dividend yield have a relatively small influence on the fair value. An increase of the risk-free rate and a decrease of the expected dividend yield increase the fair value of the option. A special case is the parameter for the annual post-vesting exit rate $\left(w_{2}\right)$. An increase of the post-vesting exit rate increases the fair value of the option if and only if the post-vesting exit rate has no influence on the expected life. The reason for this is that if the model is calibrated to a certain expected life (in the example: five years), a change of the postvesting exit rate changes also the exercise scheme relative to the expected life. Therefore, if the expected life is fixed, an increase of the postvesting exit rate increases the fair value. For large changes of the post-vesting exit rate, the estimation of the expected life has to be adjusted (decreased for high exit rates and increased for low exit rates, relative to standard situations). Below we show that for large changes of the parameters $S, X, T, v$, and $w_{2}$, the exercise scheme changes and the expected life $E L$ (or the exercise accelerator $M^{*}$ ) has to be adjusted accordingly.

Figure 1 shows the value of an employee stock option depending on the expected life and the volatility. The contractual life $T$ or maturity (7 


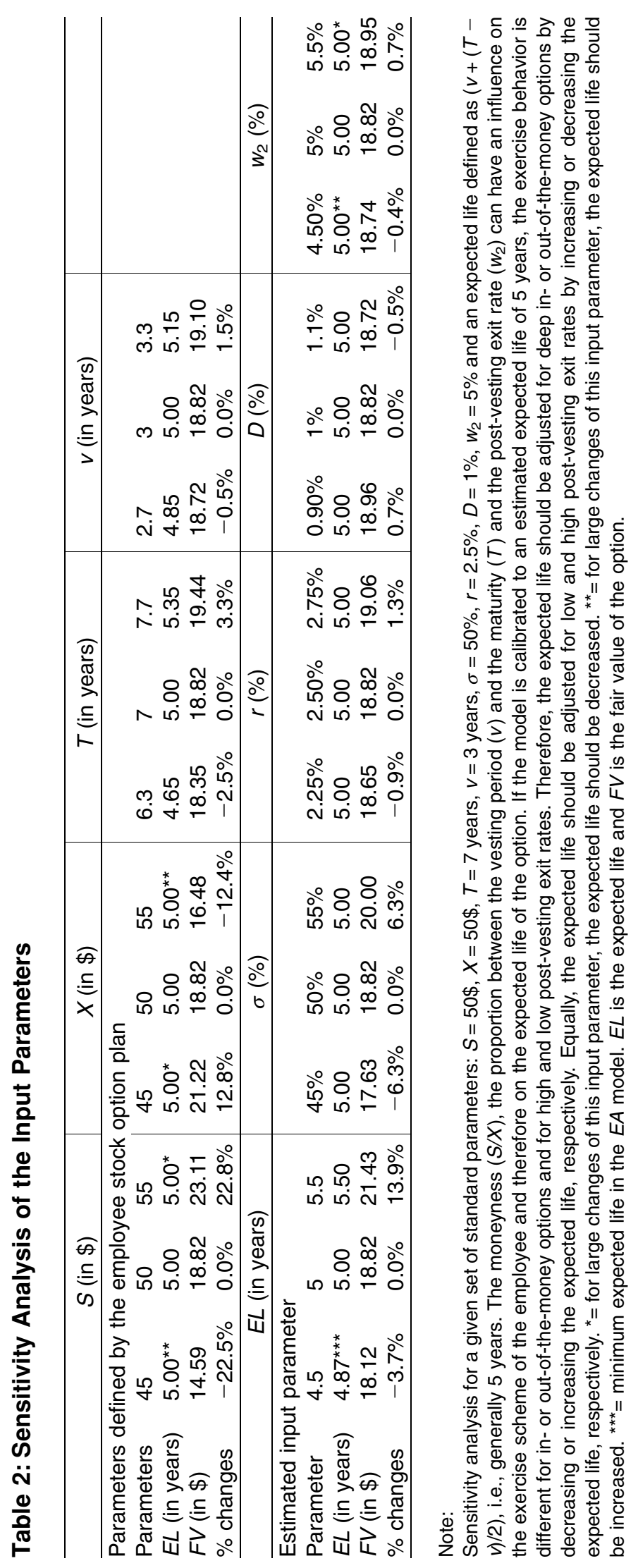


Figure 1: Fair Value of the Option with Respect to Expected Life and Volatility

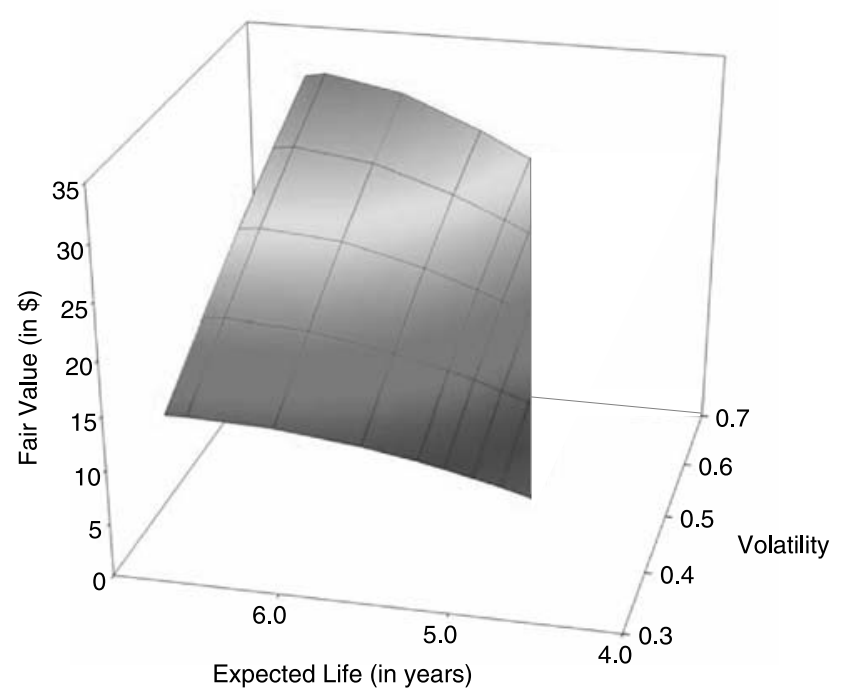

This figure shows the fair value of the option with respect to the expected life and the volatility. All other parameters are the same as in Table 1 for the standard example $(S=50 \$, X=50 \$, T=7$ years, $v=3$ years, $\left.r=2.5 \%, D=1 \%, w_{2}=5 \%\right)$.

years) cannot be reached because the non-zero post-vesting exit rate $(5 \%$ p.a.) implies an expected life of less than the maturity of the option. Furthermore, there is a minimum expected life (min $E L$ ) for all volatilities and an expected life equal to the vesting period ( 3 years) is not possible due to the expectation character of the model.

The firm defines the following characteristics of an employee stock option plan: (1) the maturity and the vesting period and (2) the grant date (or the stock price) and the strike price of the option. Figure 2 shows the fair value of the employee stock option with respect to the maturity and the vesting period. All parameters are the same as in the standard example of Table 1 except for the expected life that is set to the middle of the exercisable period $(v+(T-v) / 2)$. This adjustment causes the exercise behavior to remain similar. As we have shown above, the fair value of the employee stock option increases with an increase in the maturity and the vesting period. Point 1 in Figure 2 is the standard case with a maturity of seven years and a vesting period of three years, which results in a fair value of $\$ 18.82$. Using the Enhanced American model the characteristics of the option can be modeled with different maturities and vesting periods that give the same fair values (line between the points 1,2 and 3 in Figure 2). In Figure 2, the option values of the standard Black-Scholes model are also shown. The reduction between the option value of the Black-Scholes model and the Enhanced American model for large maturities and small vesting periods can be huge. If the maturity equals the vesting period $(T=v)$, the Enhanced American values and the Black-Scholes values converge because the employees cannot exercise the option early (point 4 in Figure 2).

Figure 3 shows the fair value with respect to the expected life and the moneyness $(S / X)$ of the option, where $S=\$ 50$ and $X$ varies between $\$ 38.5$ and $\$ 71.4$ (moneyness $S / X$ between 1.3 and 0.7). All other parameters are the same as in the standard example of Table 1. As we have shown above, the fair value of the employee stock option usually increases with an increase in the expected life. For a given expected life, an increase of the strike price reduces the fair value significantly. However, for options that are deep in- or out-ofthe-money at the grant date, the expected life of the option should be adapted (compared to a standard case that estimates an expected life of five years) because expected life is probably not independent of the moneyness of the option on the grant date.

\subsection{Changing Exercise Behavior and Exercise Scheme}

In this sub-section, we analyze the changing exercise behavior and exercise scheme for varying input parameters. Above we have seen that the moneyness $(S / X)$ can trigger early or late exercise, 


\section{Figure 2: Changes of the Plan Parameters: Maturity and Vesting Period}

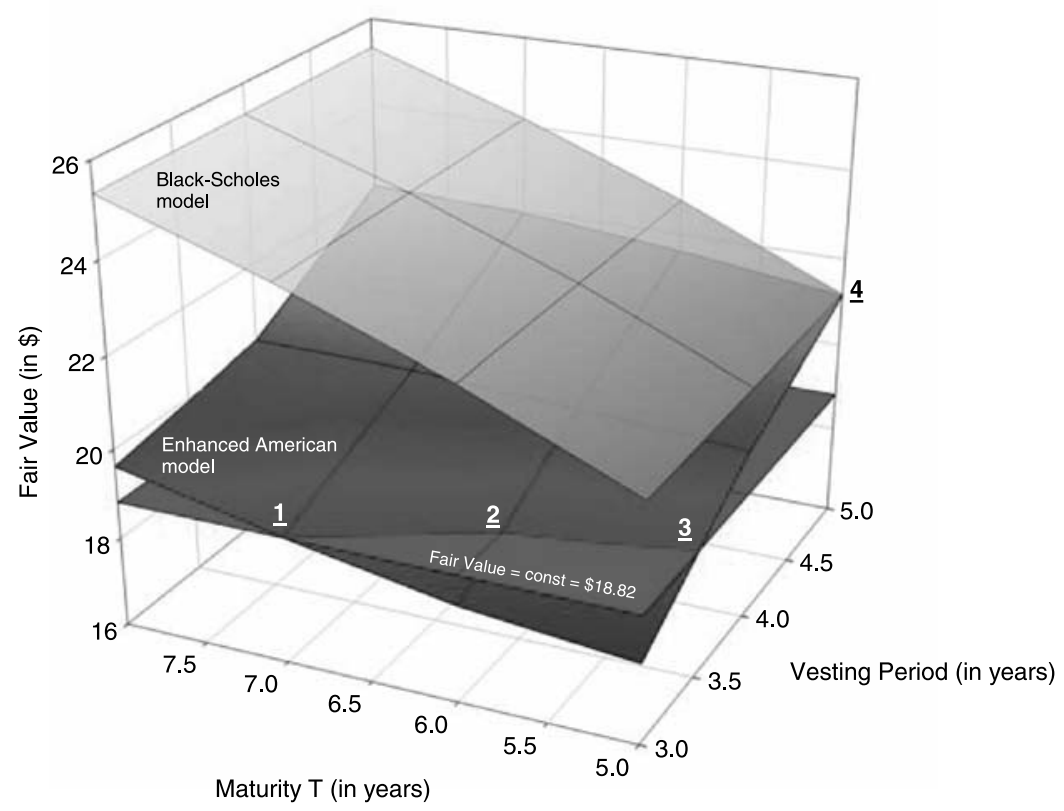

This figure shows the fair value of the option with respect to the maturity and the vesting period. The expected life is estimated in the middle of the exercisable period $(v+(T-v) / 2)$. All other parameters are equal to the standard parameters of Table $1(S=50 \$, X=50 \$, \sigma=50 \%, r=$ $2.5 \%, D=1 \%, w_{2}=5 \%$ ). The fair values on the horizontal plane have a value of $\$ 18.82$ (this is the fair value given by the standard example in Table 1).

that the proportion between the vesting period and the maturity of the option $(v / T)$ restricts the expected life of the option, and that the postvesting exit rate $\left(w_{2}\right)$ can trigger early exercise of the options. There are two possibilities to calibrate the model to a specific exercise behavior/scheme: (1) estimating the expected life $(E L)$ for a given set of input parameters (taking into account the moneyness, the proportion between the vesting period and the maturity and the post-vesting exit rate), and (2) estimating the exercise accelerator $M^{*}$. Both methods determine the exercise scheme within the binomial tree.

Figure 4 shows the relationship between the expected life $(E L)$ and the exercise accelerator $\left(M^{*}\right)$ and the resulting fair value of the option. The fair value of the option is a function of the expected life and the exercise accelerator. The exercise accelerator increases with an increasing expected life (and vice versa). Exercise accelerators below one accelerate (and therefore result in sub-optimal) exercise and exercise accelerators above one delay (and therefore also result in suboptimal) exercise.

Figure 5 illustrates the effect of changing exercise schemes and the possibilities to fix either the expected life $(E L)$ or the exercise accelerator $\left(M^{*}\right)$ for a given set of input parameters (taking into account the proportion between the vesting period and the maturity). Figure 5(a) shows that the fair value decreases with an increasing vesting period if and only if the expected life is kept constant at 5 
Figure 3: Changes of the Plan Parameters: Initial Share Price and Strike Price

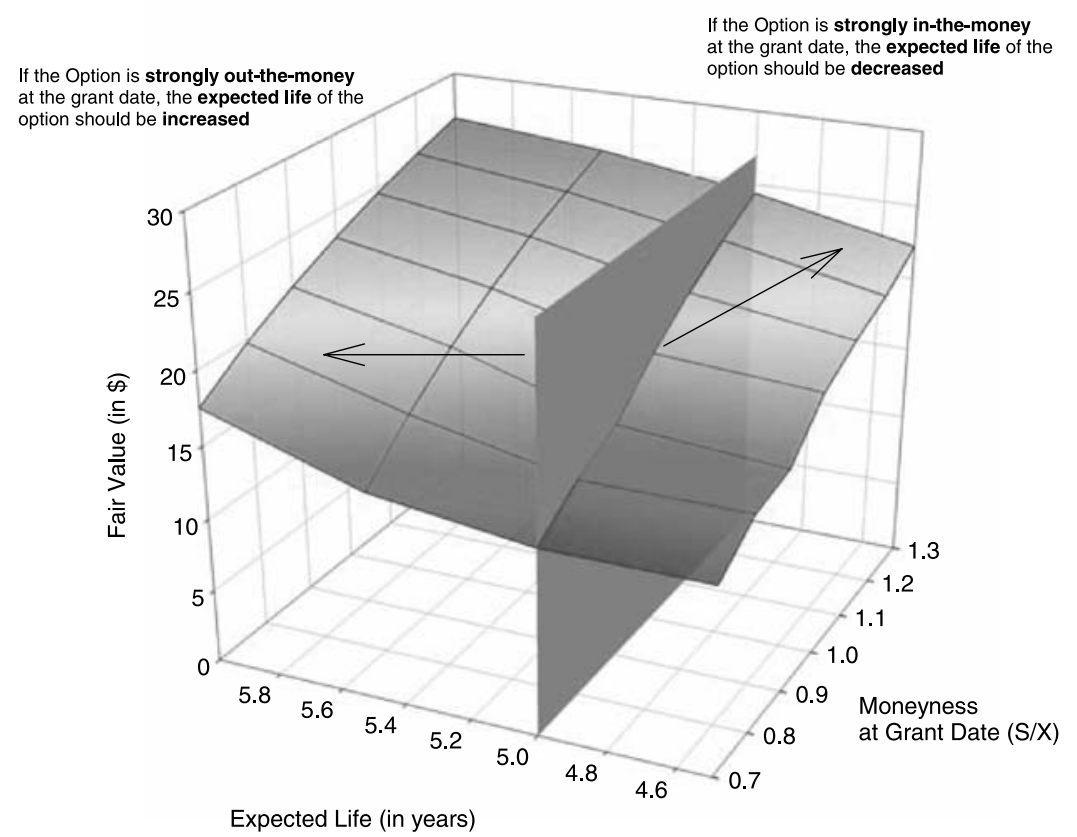

This figure shows the fair value of the option with respect to the expected life and the moneyness $(S / X)$. The initial stock price is fixed at $\$ 50$ and the strike price varies between $\$ 38.5$ and $\$ 71.4$. All other parameters are the same as in Table 1 for the standard example ( $T=$ 7years, $v=3$ years, $\sigma=50 \%, r=2.5 \%, D=1 \%, w_{2}=5 \%$ ). All fair values on the vertical plane have an expected live of five years (initial estimation for a maturity of seven years and a vesting period of three years).

years. The fair value decreases because the exercise accelerator $M^{*}$ decreases, indicating that the exercise scheme changes (employees tend to exercise their options earlier). Figure 5(b) shows that the fair value increases with an increasing vesting period if and only if the exercise accelerator $\left(M^{*}\right)$ is kept constant at 0.949 (the exercise boundary is fixed within the binomial tree which corresponds to an expected life of 5 years for the standard parameters of Table 1). The fair value increases because the expected life $(E L)$ increases and indicates that the exercise behavior changes (employees tend to exercise their options later, due to the increasing vesting period). Moreover, Figure 5 shows that the expected life and the exercise accelerator are interdependent parameters that cannot be determined independently (especially for input parameters that influence the exercise scheme such as $S / X, v / T$ and $w_{2}$ ).

Table 3 shows the value of the employee stock options determined with three different models: the Enhanced American model (EA-model) proposed in this article, the adjusted Black-Scholes model (adj BS), which replaces the maturity with the expected life and the standard Black-Scholes model (BS). Furthermore, Table 3 allows for different exercise schemes to account for the changing input parameters (the expected life is fixed in Panel A, and the exercise accelerator is fixed in Panel B). Panel A shows that if the expected life is set to five years, the exercise accelerator and the EA fair value (determined with 
Figure 4: Fair Value of Employee Stock Options for Changing Exercise Schemes

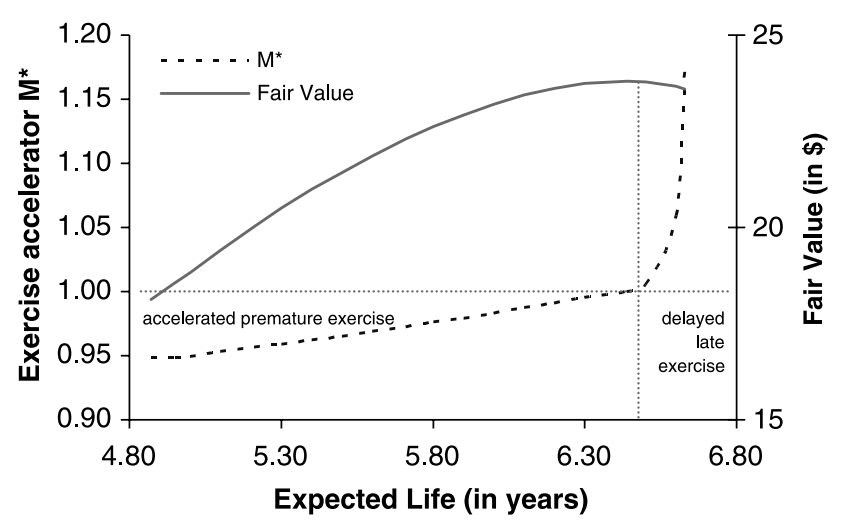

Exercise accelerator $M^{*}$ and fair value of employee stock options with respect to the expected life; $(S=\$ 50, X=\$ 50, \sigma=50 \%, r=$ $2.5 \%, D=1 \%, T=7$ years, $w_{2}=5 \%, v=3$ years). The limit for an exercise accelerator $M^{*}=1$ is given by a standard American model adjusted for the post-vesting exit rate and the vesting/blocking period. Exercise accelerators below one accelerate exercise and exercise accelerators above one delay exercise. the EA model) increases for an in-the-money grant. However, Panel B shows that if the exercise accelerator $M^{*}$ is set to 0.949 (this corresponds to an expected life of five years in the standard example), the expected life is reduced to 4.85 years for an in-the-money grant $X=45.5$. This is exactly the effect illustrated in Figure 3. In Panel $A$, an increase of the vesting period slightly decreases the EA fair value of the option. However, Panel B shows that an increase of the vesting period increases the EA fair value of the option significantly (EA fair value of $\$ 15.29$ compared to $\$ 8.76$ ). This increase deals with the different expected lives (vesting periods of $0,1.5$ and 3 years have expected lives of 1.90, 3.77, and 5 years, respectively). The expected life in Panel $B$ gives an indication of when the options are exercised (5 years for the standard example, slightly above and below 5 years for out- and inthe-money options, respectively, strongly reduced expected lives for small vesting periods and

Figure 5: Exercise Schemes and Fair Values for Changing Vesting Periods

(a) expected life fixed at 5 years

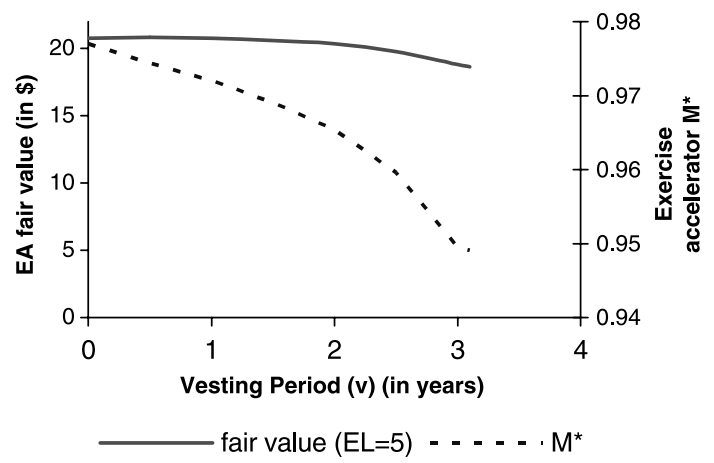

(b) exercise accelerator $M^{\star}$ fixed at 0.949

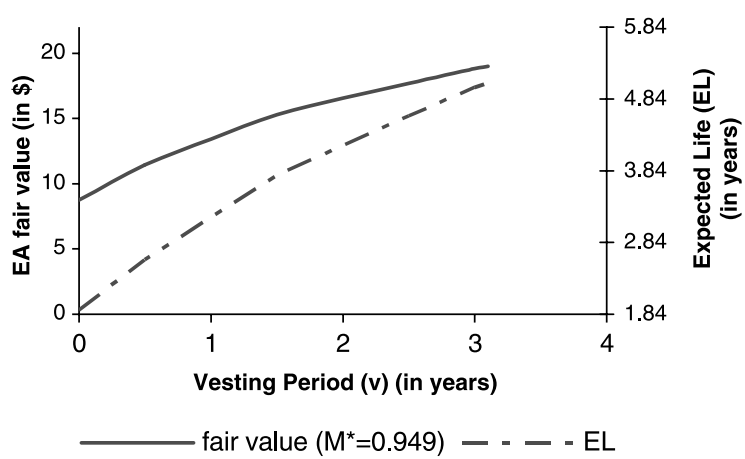

Fair value of employee stock options and exercise accelerator/expected life with respect to the vesting period $v,(S=\$ 50, X=\$ 50, \sigma=$ $50 \%, r=2.5 \%, D=1 \%, T=7$ years, $w_{2}=5 \%$ ). Figure (a) shows that the fair value decreases with an increasing vesting period if and only if the expected life is fixed at 5 years. The fair value decreases because the exercise accelerator $M^{*}$ decreases and this indicates that the exercise scheme changes (employees tend to exercise their options earlier). Figure (b) shows that the fair value increases with an increasing vesting period if and only if the exercise accelerator is fixed at 0.949 . The fair value increases because the expected life $E L$ increases and indicates that the exercise behavior changes (employees tend to exercise their options later, due to the increasing vesting period). 
Table 3: Changing Exercise Schemes and Sensitivity Analysis

\begin{tabular}{|c|c|c|c|c|c|c|c|c|c|c|}
\hline \multirow[b]{2}{*}{$x$} & \multirow[b]{2}{*}{$v$} & \multirow[b]{2}{*}{$w_{2}$} & \multicolumn{4}{|c|}{$\begin{array}{c}\text { Panel A: Expected Life } \\
E L=5 \text { years }\end{array}$} & \multicolumn{4}{|c|}{$\begin{array}{l}\text { Panel B: Exercise Accelerator } \\
\qquad M^{*}=0.949\end{array}$} \\
\hline & & & $E A$ & $M^{*}$ & $\begin{array}{l}\text { adj } B S \\
(T=5 \mathrm{y})\end{array}$ & $\begin{array}{l}B S \\
(T=7 \mathrm{y})\end{array}$ & $E A$ & $E L$ & $\begin{array}{l}\text { adj } B S \\
(T=E L)\end{array}$ & $\begin{array}{l}B S \\
(T=7 \mathrm{y})\end{array}$ \\
\hline 50 & 3 & $5 \%$ & 18.82 & 0.949 & $+13 \%$ & $+28 \%$ & 18.82 & 5.00 & $+13 \%$ & $+28 \%$ \\
\hline 55.5 & & money & 16.24 & 0.946 & $+22 \%$ & $+41 \%$ & 17.22 & 5.13 & $+16 \%$ & $+33 \%$ \\
\hline \multirow[t]{5}{*}{45.5} & & & 20.98 & 0.954 & $+7 \%$ & $+20 \%$ & 20.17 & 4.85 & $+10 \%$ & $+25 \%$ \\
\hline & 0 & & 20.78 & 0.977 & $+2 \%$ & $+16 \%$ & 8.76 & 1.90 & $+57 \%$ & $+176 \%$ \\
\hline & 1.5 & & 20.61 & 0.969 & $+3 \%$ & $+17 \%$ & 15.29 & 3.77 & $+23 \%$ & $+58 \%$ \\
\hline & & 0 & 18.18 & 0.948 & $+17 \%$ & $+33 \%$ & 19.07 & 5.21 & $+13 \%$ & $+27 \%$ \\
\hline & & $10 \%$ & 19.69 & 0.957 & $+8 \%$ & $+23 \%$ & 18.06 & 4.72 & $+15 \%$ & $+34 \%$ \\
\hline
\end{tabular}

Note:

Table 3 shows a sensitivity analysis of the fair value with respect to the input parameters that are relevant for the exercise scheme, among other things. $X$ is the strike price, $v$ is the vesting period, and $w_{2}$ is the post-vesting exit rate. This example uses the standard parameters of Table $1(S=50 \$, T=7$ years, $\sigma=50 \%, r=2.5 \%, D=1 \%$ ). The expected life is fixed in panel A and the exercise accelerator is fixed in Panel B. Panel A shows that the exercise accelerator $\left(M^{\star}\right)$ changes when the input parameters changes. Panel B shows that the expected life $(E L)$ changes when the input parameters changes. The table shows a model comparison of three valuation models: $E A$ is the Enhanced American model, adj $B S$ is the adjusted Black-Scholes model that replaces the maturity with the expected life and $B S$ is the standard Black-Scholes model with a maturity of 7 years.

slightly above and below 5 years for low and high post-vesting exit rates, respectively). Furthermore, Table 3 shows that the reduction of the EA fair value compared to the (adjusted) Black-Scholes model can be substantial.

\section{Conclusion}

In this paper, we show how employee stock options can be valued under the new reporting standards IFRS 2 and FASB 123 (R) for sharebased payments. Both standards require firms to expense employee stock options at fair value. We propose a new valuation model, referred to the Enhanced American model, which conforms to the new standards and results in fair values often much smaller than the values generated by closedform models such as the Black-Scholes or the adjusted Black-Scholes model. We conduct a sensitivity analysis of model input parameters and show that the moneyness, the proportion between the vesting period and the maturity, and the post-vesting exit rate not only influence the fair value of the option, but also the exercise scheme. The analysis shows that it is important to consider the model input parameters when calibrating the model to the estimated expected life or the exercise scheme because the exercise behavior can be sensitive to the other input parameters.

\section{Acknowledgements}

We would like to thank Bernd Brommundt, Alexander Ising, Axel Kind, Stephan Süss, Rico von Wyss, Michael Verhofen, Andreas Zingg, and a referee for their helpful comments. 


\section{ENDNOTES}

[1] See especially LAMBERT et al., (1991), SMITH and ZIMMERMAN (1976), KULATILAKA and MARCUS (1994), RUBINSTEIN (1995), CARPENTER (1998), DE TEMPLE and SUNDARESAN (1999), HALL and MURPHY (2000a, 2000b, 2002).

[2] The EA model proposed in AMMANN and SEIZ (2004) is slightly different to the model proposed in this paper. The only difference of the two model versions is that the model in this paper only accounts for the post-vesting exit rate and not for the pre-vesting exit rate. The standards prescribe to account for the pre-vesting exit (termination during the vesting period) by applying the "modified grant date method".

[3] See HULL and WHITE (2002).

[4] For larges values of the expected life, it is possible that an increase of the expected life can reduce the fair value of the option, but if and only if the underlying stock pays dividends (see AMMANN and SEIZ (2004)).

\section{REFERENCES}

AMMANN M. and R. SEIZ (2004): "Valuing Employee Stock Options: Does the Model Matter?", Financial Analysts Journal 60(5), September/October.

CARPENTER, J. (1998): "The Exercise and Valuation of Executive Stock Options", Journal of Financial Economics 48(2), pp. 127-158, (May).

COX, J. C., S. ROSS and M. RUBINSTEIN (1979): "Option Pricing: A Simplified Approach", Journal of Financial Economics 7(3), pp. 229-263, (September).

CUNY, J. C. and P. JORION (1995): "Valuing Executive Stock Options with Endogenous Departure", Journal of Accounting and Economics 20, pp. 193-205.

DE TEMPLE, J. and S. SUNDARESAN (1999): "Nontraded Asset Valuation with Portfolio Constraints: A Binomial Approach", Review of Financial Studies 12(4), pp. 835-872, (Special).

FASB (1995): "FASB 123: Accounting for StockBased Compensation.", Financial Accounting Standards Board.

FASB (2004): "Statement of Financial Accounting Standard No. 123 (revised 2004), Share-Based Payment", Financial Accounting Standards Board. GARMAN, M. (1989): "Semper Tempus Fugit", Risk 2(5), pp. 34-35, (May).

GARMAN, M. (2002): "Stock Options for Undiversified Executives", Journal of Accounting and Economics 33(1), pp. 3-42, (February).

HALL, B. J. and K. J. MURPHY (2000): "Optimal Exercise Prices for Risk Averse Executives", American Economic Review 90(2), pp. 209-214, (May).

HALL, B. J. and K. J. MURPHY (2000): "Optimal Exercise Prices for Risk Averse Executives", American Economic Review 90, pp. 209-214, (May).

HALL, B. J. and K. J. MURPHY (2002): "Stock Options for Undiversified Executives", Journal of Accounting and Economics 33, pp. 3-42.

HUDDART, S. (1994): "Employee Stock Options", Journal of Accounting and Economics 18(2), pp. 207-231, (September). 
HUDDART, S. and M. LANG (1996): "Employee Stock Options Exercises: An Empirical Analysis", Journal of Accounting and Economics 21(1), pp. 5-43, (February).

HULL, J. and A. WHITE (2002): "Determining the Value of Employee Stock Options", Report produced for the Ontario Teachers Pension Plan.

HULL, J. and A. WHITE (2003): "Accounting for Employee Stock Options", Working paper, University of Toronto.

HULL, J. and A. WHITE (2004): "How to Value Employee Stock Options", Financial Analysts Journal 60(1), pp. 114-119, (January/February).

IFRS 2 (2004): "International Financial Reporting Standard, IFRS 2, Share-based Payment”, International Accounting Standards Board.

JENNERGREN, L. and B. NASLUND (1993): "A Comment on 'Valuation of Executive Stock Options and the FASB Proposal'", Accounting Review 68(1), pp. 179-183, (January).

KULATILAKA, N. and A. J. MARCUS (1994): "Valuing Employee Stock Options", Financial Analyst Journal 50(6), pp. 46-56, (November/December).

LAMBERT, R. A., D. F. LARCKER and R. E. VERRECCHIA (1991): "Portfolio Considerations in Valuing Executive Compensation", Journal of Accounting Research 29(1), pp. 129-149, (Spring).

RUBINSTEIN, M. (1995): "On the Accounting Valuation of Employee Stock Options", Journal of Derivatives 3(1), pp. 8-24, (Fall).
SMITH, C. W. and J. L. ZIMMERMAN (1976): "Valuing Employee Stock Option Plans Using Option Pricing Models", Journal of Accounting Research 14(2), pp. 357-364, (Autumn).

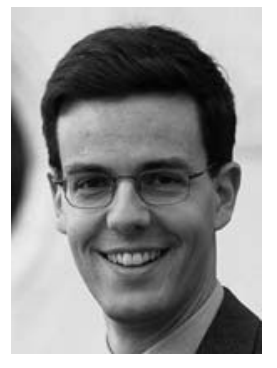

Manuel Ammann is professor of finance at the University of St. Gallen and director of the Swiss Institute of Banking and Finance. He is also the academic director of the University of St. Gallen's M.A. and Ph.D. programs in banking and finance. His main research interests are in the areas of derivative securities, asset management, financial markets, and risk management. In addition to his academic activities, he serves as a director and trustee to several Swiss companies and foundations, respectively.

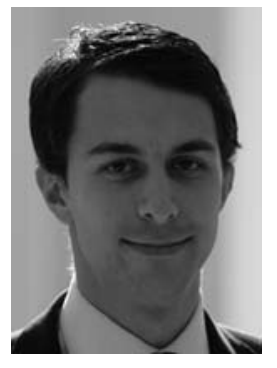

Ralf Seiz studied physics at ETH in Zurich, Switzerland. Since November 2002 he is a doctoral student at the University of St. Gallen and works as a research assistant at the Swiss Institute of Banking and Finance. His research interests are in the field of hybrid securities and derivatives. 